\title{
Vanguardia vestida de folletín. Una lectura de Emelina, novela chilena de Rubén Darío (y Eduardo Poirier)
}

Eva Valcárcel ${ }^{1}$

Resumen. En estas páginas nos acercaremos al análisis de la primera novela que lleva la firma de Rubén Darío. Emelina, escrita en coautoría con Eduardo Poirier en 1886 y publicada en 1987. Se trata de un texto que reúne ciertas particularidades. Por una parte, es la primera novela de un gran artista aún muy joven, aunque en plenitud de su talento. Técnicamente, utiliza recursos que serán elaborados posteriormente por la vanguardia, como las apelaciones al lector, la introducción del autor en el texto, cierta exhibición del proceso de elaboración de la obra, la narración por medio de textos externos como las noticias de prensa y las cartas leídas por los personajes, alejando así la verosimilitud frente a lo verídico reclamado desde la ficción.

Palabras clave: Rubén Darío; Emelina; Eduardo Poirier; novela; folletín; vanguardia.

[en] Avant-garde Dressed up as Folklore. A Reading of Emelina, a Chilean Novel by Rubén Darío (and Eduardo Poirier)

\begin{abstract}
In these pages we will approach the analysis of the first novel that bears the signature of Dario. Emelina, written in co-authorship with Eduardo Poirier in 1886 and published in 1987. It is a text that meets certain particularities. On the one hand, it is the first novel by a great artist who is still very young, although at the height of his talent. Technically, it uses resources that will be elaborated later by the avant-garde, such as appeals to the reader, the author's introduction in the text, a certain exhibition of the process of elaboration of the work, the narration through external texts such as press releases and letters read by the characters, thus distancing the verisimilitude against the truth claimed from fiction.
\end{abstract}

Keywords: Rubén Darío; Emelina; Eduardo Poirier; novel; feuilleton; avant-garde.

Cómo citar: Valcárcel, E. (2020) Vanguardia vestida de folletín. Una lectura de Emelina, novela chilena de Rubén Darío (y Eduardo Poirier), en Anales de Literatua Hispanoamericana 49, 125-132.

Rubén Darío como novelista ha recibido menos halagos y algunos reproches de parte de la crítica, que consideró que las novelas del gran Darío no estaban a la altura de su probado talento. Y se han escatimado estudios sobre esas obras, sin duda importantes, del autor.

En estas páginas nos acercaremos al análisis de su primera novela, Emelina, escrita en 1886 y publicada en $1987^{2}$. Se trata de un texto que reúne ciertas particularidades; por una parte, es la primera novela de un gran artista aún muy joven aunque en plenitud de su talento, y otra característica que la singulariza es la coautoría. Y la coautoría de la obra, firmada con Eduardo Poirier, es un entretenimiento para la crítica, ya que, a buen seguro, ninguno de los dos autores quiso significarse. De ese modo no sabremos nunca la responsabilidad del nicaragüense en cada página.

Estamos entonces ante un ejercicio de coautoría de Darío novelista, en un género folletinesco no exento de elaborados matices modernos; por lo tanto, una obra de menos escaso interés del que se le atribuyó en

${ }^{2}$ La novela se publicó por primera vez en Valparaíso, en 1887; la impresión estuvo a cargo de Imprenta y Litografía Universal de Chaigueau y Castro y en ella figura Francisco Poirier como autor antes que Darío. Esta edición es la que utilizamos en las citas textuales de este artículo, identificadas por el número de página. En 1927, Francisco Contreras edita la novela en París, en la Agencia Mundial de Librería, y escribe un prólogo al texto. En esta edición aparece Darío como autor y una nota que dice que ha sido escrita en colaboración con Eduardo Poirier. 
ocasiones, incluso por el mismo Darío, que la denominó un pecadillo de su juventud. La escribió en Chile, a donde llegó con 19 años, y en donde pasó un tiempo recordado con felicidad en su autobiografía. En este contexto de bienestar emocional y con escaso dinero, escribió Emelina con su amigo chileno Poirier, quien era traductor de folletines europeos en el diario El Mercurio, a cuyo director, Agustín Edwards, dedicará la obra $^{3}$.

Francisco Contreras ${ }^{4}$, en la edición parisina de la novela, en 1927, considera que Darío mejoró la propuesta de Poirier y consolidó el núcleo narrativo e introdujo algunos nombres clave como el de la protagonista, Emelina, que recuerda a la mujer de Darío Rosario Emelina Murillo; el del hombre bueno y virtuoso, Marcelino Gavidia, teniente de la tercera compañía de bomberos de Valparaíso; o el de la caricatura del hombre de estado, Antonio Guzmán Blanco, "el pavo real de Venezuela"; el personaje, Joaquín Ortiz Silva, Secretario de la embajada de Nicaragua en Bélgica también sería un aporte personal de Darío, según refleja Silva Castro (1934) y recoge Jorge Eduardo Arellano (2013), quien enumerará los capítulos ( I,II,V,VIII y IX de la tercera parte) de clara autoría del nicaragüense, por el estilo y la elaboración lingüística 5 .

Los autores trabajaron durante diez días, según propia confesión $(\mathrm{V})$, y se presentaron, probablemente por dinero, al certamen convocado por el diario La Unión de Valparaíso. Entre los miembros del jurado estaba Guillermo Blest Gana y Benjamín Vicuña Mackenna.

Emelina no fue premiada entonces, pero Darío fue reconocido al año siguiente en el Certamen Varela por Canto épico a las glorias de Chile. Las escasas críticas aparecieron en el diario santiaguino La Época, el 22 de noviembre de 1887, en donde se hacían eco de lo que se lee en el prólogo. Pero también de que no era una novela didáctica que "nada enseñará al lector pero que nada puede dañarlo". Otra crítica del 2 de noviembre de 1888, explicaba que "la vida social moderna palpita y centellea en las páginas de Emelina, constituyendo su mayor atractivo y novedad." (Silva Castro: 1934).

Buscando esta vida moderna representada en el texto nos acercamos a la obra, en la que encontramos esperadas características del folletín, sin embargo coexisten técnicas que enriquecen el folletín y hacen de la obra un documento de notable interés en cuanto iniciador de una propuesta literaria que persigue la utilización de modos narrativos inusuales y que son los que nos conducen por lugares menos transitados y más inesperados, hacia un camino de modernidad y que se puede entender como precursor de algunos textos de vanguardia. En definitiva, buscamos encontrar ahí la verdadera vida que buscaban los surrealistas; en este punto recordemos que la vanguardia tuvo su querencia por el folletín, que para los surrealistas era una forma posible escritura automática y en la búsqueda de lo elemental, lo primordial y lo humano, encontraban la vida auténtica.

La necesidad de los rasgos folletinescos venía impuesta por la convocatoria del certamen, pero Darío y Poirier eligieron escribir de manera irónica y lúdica sobre la misma novela que estaban elaborando, pudiendo sobrepasar con creces lo que se esperaba del folletín y acercarse a un modelo de mayor rango artístico. El siglo XIX encuentra en la forma del folletín ${ }^{6}$ un instrumento de exposición de las virtudes y vicios de la sociedad urbana que se refleja en ella de manera hiperbolizada, como una caricatura inflexible. La realidad ficticia recreada en la escritura es claramente inverosímil porque no busca la apariencia de $\operatorname{verdad}^{7}$, ni

${ }^{3}$ Después de la dedicatoria inicial, se incluye una carta de Darío a Poirier y una respuesta de éste. En estas páginas se habla de la novela, de su sencillez, de sus faltas posibles: "tiene el tropiezo del primer libro", (V) y también de su marcado carácter truculento, "escenas espeluznantes" dice Darío y Poirier las justifica explicando que son preferibles a aquellas que emplea "el género realista que, contrayéndose á pintar de aquello que vemos en el comercio diario de la vida lo más repelente ó craso, como varias de las de Zola" (VII).

${ }^{4}$ En el prólogo, Contreras califica como defectos algunas de las características del texto que tienen un tratamiento paródico, como son las descripciones esquemáticas de las grandes urbes y las frecuentes apelaciones al lector; rasgos que pueden ser leídos como signos de renovación.

${ }^{5}$ Dolores Phillipps-López apunta que Contreras no se dio cuenta de lo que estaba viviendo Darío en su vida personal estaba reflejado en la novela a través de cuadros de costumbres, pero también "en la percepción, que comienza entonces a manifestarse, de las ambigüedades de lo moderno..."

(Phillipps-López 1998, 217)

${ }^{6}$ Las mujeres fueron lectoras privilegiadas del folletín, que con el tiempo alejó a los plutócratas, siempre masculinos, que tal vez se veían reflejados de un modo poco favorable porque el folletín adquirió un carácter de discurso alternativo frente al dominante y rechazados por el estado y la Iglesia. Por lo tanto, estamos ante una forma revolucionaria que ayudó con éxito a propagar en Chile ideas afrancesadas, por el origen del feuilleton, que se deriva de feuille, hoja, y europeas en general.

${ }^{7}$ El escritor Mario Vargas Llosa expresó en 1982, en el marco del XXX Festival de Cine de San Sebastián, durante una mesa redonda la opinión de que el folletín convergía con la novela medieval de caballerías:” En realidad yo creo que sus orígenes (del folletín) son bastantes más antiguos y que el folletín es una versión decimonónica de lo que fue la novela de caballería medieval. Se pueden encontrar una serie de similitudes en la visión del mundo que ofrecen el folletín y la novela de caballería, tanto en la concepción del mundo como en las técnicas de que se valen sus autores para recrear o, mejor dicho, crear su propia realidad. Creo que el folletín no es un reflejo de la realidad, sino que es una realidad paralela, una realidad autónoma, o, si se prefiere, es esencialmente una irrealidad." 
ajustarse a las reglas del mundo objetivo, sino que se adecúa a sus reglas particulares, simples y seguras y que pertenecen al mundo de la ficción. La artificialidad se exhibe, y no como un demérito. Esta cualidad es la que nos acerca a un modelo estético vanguardista, en el que los procesos de la creación artística constituyen en sí mismos parte de la obra y se presentan como conjuro para alejar toda sospecha de verosimilitud. Encontraremos múltiples anécdotas que convergerán en una historia de cierta complejidad en la narración de los hechos. La historia amorosa principal se desdoblará y nos encontraremos con un paralelismo: dos mujeres y dos hombres virtuosos y las correspondientes bodas en sus ambientes, aristocrático uno, y campesino el otro. Se ritualiza un modelo social rígido y simple, con facilidad aparente en su lectura, lo que buscaban las entregas folletinescas, y que los autores denominan como género espeluznante, término que estaría en el mismo ámbito teórico que el folletín. Evidenciamos aquí la crítica y la ironía que más tarde introducirá al lector dentro de la obra, como responsable de opinión de las historias narradas.

Emelina nos muestra ciertas costumbres de la sociedad en general, pero más aún, de la sociedad chilena urbana, en particular; sus ciudades, sus lugares de veraneo, las relaciones sociales.

Escribe José Zamudio:

La necesidad de un folletín nacional se impuso cuando se quiso hacer balance de los problemas locales, que hacían aún más fiel al público, cuando se introducían temas patrióticos, guerras o se ponía ante los ojos la vida en las nuevas ciudades, la sociedad moderna que se estaba constituyendo y que inventaba nuevos modos de relación, nuevas profesiones, entretenimientos y modas en el arreglo personal; o retrataba vicios secretos, males crónicos que aparecían con la ciudad moderna, el dinero y su administración, y sus efectos, por ejemplo". (Zamudio 1973: 40)

Estas palabras nos hacen entender que es una novela profundamente chilena ${ }^{8}$, para un público chileno, por eso las anotaciones sobre la guerra del pacífico con un episodio dramático y heroico, y por eso también tiene sentido la introducción del cuadro costumbrista final de la boda, así como las frecuentes alusiones a las maravillas de Valparaíso y de Viña; no en vano es el lugar al que deciden regresar los personajes para vivir su vida sana, donde hallan la felicidad y la bondad, mientras en París y Londres, ciudades en las que la moral y la decencia se han visto afectadas por el dinero, elemento moderno, y configurador de las urbes europeas desde entonces, imprescindible para entender el relato de Emelina. El dinero trae gracias y desgracias pero siempre está presente. El tiempo de la historia está contenido en un fragmento indefinidamente extenso, está marcado en la falta de datos de años concretos más allá del siglo. En 18... (VI) es repetido en varias ocasiones, marcando el siglo contemporáneo de la escritura pero sin decidirse por año alguno, aunque se fijan las estaciones del año, porque los meses son necesarios para la recreación efectiva de la historia. El verano, el veraneo o la primavera son estados emocionales en sí, y animan a presentar la sociedad que les interesa: aquella que luce con trajes y joyas su belleza en escenas de galanteo en hoteles de veraneo de lujo en un contexto de apacible calma, así es el Hotel de Viña del Mar.

Pero el tiempo indefinido no nos conduce a una escritura eterna, la cuestión se resuelve, de un modo esperado, pero también anticipado; la novela adelanta y se adelanta a la historia, se explica y en esos vertiginosos paseos, va añadiendo detalles técnicos heterogéneos. No podemos decir que el encadenamiento de los capítulos sea automático, rígido o repetitivo. Significativo es el ejemplo de la primera parte, en la que los capítulos X y el XI aparecen unidos en una sola frase que comienza en final el capítulo X y termina en el inicio del capítulo XI. La frase es: “...porque si no os condecoraría” (82 y 83) y quien habla es "el ilustre americano".

La novela está introducida por dos textos previos; una dedicatoria a Agustín Edwards, por parte de Poirier, que era traductor de novelas para El Mercurio, cuyo ilustrado editor era el propio Edwards. Y un segundo texto, un prólogo (VII), que reproduce una carta de Darío a Poirier y una respuesta de éste. El prólogo es una excusa para despertar el interés del lector y captar su atención; en él expresan sus deseos de haber escrito una novela digna, aunque modesta: "hemos pretendido el esmero de la forma y la bondad del fondo, sin seguir para lo primero lo que llama Janin folies du style en délire, ni para lo segundo el ramillete de divinas flores $(\mathrm{V})$; es decir, han procurado un equilibrio, un control de la exageración. Su debilidad, confiesan, es la que manifestó Goncourt: "Nosotros no hemos tenido la visión directa de lo humano, sino

${ }^{8}$ Francisco Domingo Sarmiento fue el responsable de la primera publicación de un folletín en Chile, cuando estaba a cargo del diario santiaguino El Progreso, en 1842 . 
recuerdos y reminiscencias de cosas vistas en los libros." (VI). Modelos poco moldeables con deficiencias para la complejidad emocional, la escasez de mundo interno propia del folletín, así ellos declaran su elección. Estas son palabras de Darío a las que replica Poirier celebrando lo espeluznante como un mérito que propicia el profundo interés dramático de esta obra, un rasgo necesario, que compara a "esas novelas del género realista que contrayéndose a pintar aquello que vemos en el comercio diario de la vida lo más repelente o craso, como varias de Zola..." (VIII) Interesante apunte contra el realismo, la representación del mundo tal como lo vivimos y una decidida apuesta por la superación de la verosimilitud y la mímesis. Y es una novela "bien intencionada y sana", dice, así como" interesante para las lectoras mujeres, a quienes ha tenido en cuenta al construir la trama y describir las escenas"9. (VIII).

Tenemos pues una declaración de intenciones: los autores han creado un folletín, han introducido efectismo paródico y están en contra de los modelos miméticos, contra el realismo y aún el naturalismo.

Las cuatro partes de la narración se estructuran en diferente número de capítulos; 5 capítulos la primera y cuatro la cuarta; las partes centrales, segunda y tercera, serán más largas y constarán de 11 y 13 capítulos. La estructura presenta un diseño geométrico en el que existe un marco, ( 1 y 4 ) y un centro ( 2 y 3 ). Dos partes centrales que tratan el desarrollo de la trama espeluznante en el pasado, y una primera y cuarta que vuelven al presente en el que la historia ha encontrado un desenlace reparador. Es decir, la primera parte y la cuarta forman una novela sentimental en la que dos parejas de enamorados se cortejan y se casan. La tercera y la cuarta contienen la causalidad truculenta de las dos anteriores y que constituye cuerpo del relato.

En la primera parte asistimos a un incendio en Valparaíso que propicia el encuentro entre los que acabarán siendo los enamorados. La descripción de ese incendio es de una insistente agilidad, la lengua es rápida, atropellada, la narración nerviosa, como corresponde a la agitación del hecho, esto sucede de manera notable varias veces en el texto configurándose así una percepción múltiple de la situación narrada:

Voluntarios que a toda prisa abandonan unos el abrigado lecho, otros el aristocrático salón de animada tertulia, y vuelan a sus casas en busca de alguna insignia de su misión para correr en seguida a sus cuarteles; bombas que han partido ya con presura al lugar amagado; auxiliares que olvidando el cansancio producido por la fatigosa labor del día, acuden ágiles a secundar a sus oficiales; muchachos y hombres del pueblo que ocurren a prestar el contingente de sus brazos para arrastrar las pesadas máquinas que evitan la destrucción, a diferencia de otras que la realizan; aquí un carruaje que es uncido a la palanca de la bomba y ayuda a arrastrarla; más allá un grupo de alegres jóvenes que al salir de su club se unen al número de los entusiastas salvadores de la propiedad. (6)

El lector percibe que el grupo se acerca al objetivo y va distinguiendo las nacionalidades, los uniformes distintos de los bomberos que pasan ante nuestra mirada fija. En un instante los distinguimos diversos y luego volvemos a verlos como una masa vibrante de matices cromáticos fundidos y dinámicos. Cada cual con la enseña de su bandera, quizás, el grupo se mueve como un organismo vivo en el que destaca el color y el rápido desplazamiento que permite que percibamos una única imagen de esas individualidades afanadas en un propósito común que los une; sintácticamente, la reiteración del enlace copulativo "y" acelera la fusión de las imágenes singulares y nos acerca a un movimiento embriagador de tiovivo en el que nuestra visión desdibuja, a causa de la velocidad del giro, los límites de la realidad:

Luego, a medida que van aproximándose al lugar amenazado, vánse también distinguiendo allí bomberos de todas las nacionalidades, uniformes de diversos colores y variedades; y pasan en rápido desfile, y se confunden y se agrupan, y se estrechan las casacas rojas con las azules, los cascos de bronce con los relucientes de cuero; y se codean y se empujan y se mezclan con la admirable confraternidad del deber, ingleses y chilenos, italianos, alemanes y franceses (6).

\footnotetext{
${ }^{9}$ Las mujeres son las destinatarias iniciales del folletín; se suponía que era un entretenimiento adecuado si no alteraba el orden social. Los hombres podían sentirse retratados en algunos personajes mundanos de manera poco favorable. De este modo se pudo convertir en un vehículo del discurso secretamente disidente femenino, alejado de aquel imperante y establecido desde la masculinidad. El hecho de que se recojan calificaciones sobre estas novelas que las consideran didácticas o no, dañinas o no para las mujeres, nos hace pensar en una censura, protectora del discurso dominante, ejercida por el estado y aún por los estamentos religiosos.
} 
La ciudad de París tiene su protagonismo en el capítulo IX de la segunda parte, también atribuida a Rubén. El retrato de la ciudad es oscuro, definido como el caos, citando a Victor Hugo. El caos en donde nada se diferencia: "El buen dios puso, desmenuzados el Paraíso del bribón Mahoma, y el Infierno del visionario Dante. Vació la caja de pandora e hizo entrar una gran muchedumbre de amorcillos y tras ellos amarguras." (75) París es el placer y el castigo. La expresión es de notable interés, por las palabras y por la sintaxis. Hay un dinamismo moderno plasmado en la rapidez del texto que traza el dibujo de una ciudad en forma de fragmentos añadidos, lo que se denominó collage en la vanguardia. Escasean los puntos, la narración no se detiene sino que mira a muchas partes y coloca en simultaneidad una secuencia de acciones que veríamos, de manera sucesiva en el tiempo:

Las largas filas de coches no cesan de pasar en rápida sucesión. Aquí un elegante landó que luce corona ducal, lleva lindos palmitos. Allí una victoria conduce a un banquero o a un diplomático; y esto sucede a cada instante; hombres, mujeres, niños y niñas, de todos los tamaños; morenas, rubias, cabellos claros, cabellos oscuros, cabellos canos (77).

El narrador invita al lector a seguirlo con la lámpara maravillosa del novelista, dice, con "la que ve sin que le vean..." (76-77). En una sociedad galante aparece de nuevo "el Ilustre americano, don Antonio Guzmán Blanco, dadivoso cual monarca, Mecenas de los extraños y mecomes de su pobre patria (77). Y con rapidez el narrador nos lleva a empujones al capítulo que sigue en el salón del americano.

El capítulo II de la primera parte se alarga en un torrente de colores y acciones, pintando sin pausa un cuadro apocalíptico. Ese apocalipsis precede al sonido de la voz de una mujer en apuros, Emelina. Ella es una mujer ángel retratada de luto:

Linda joven de porte noble y airoso... de serena dulzura y gracia incomparable. Un traje de riguroso luto aprisionaba sus esbeltas formas y hacía resaltar la hermosura de su rostro hermosísimo. La expresión de melancolía que en él veíase de ordinario dibujada, añadía un misterioso atractivo a los encantos de su rara belleza. Al hablar, diríase que a sus labios asomaba algo de la tristeza dominante al parecer en su alma, y que a su acento puro y sonoro daba inflexiones tan tiernas como suaves, propias para hacer a quien la escuchaba, imaginarse estar oyendo las melodías de una voz celeste. (16-17)

Naturalmente, su retrato será el de una mujer finisecular, estéticamente vinculada a un modelo prerrafaelista, dulce y noble; bella y noble; hermosa más allá de su sexualidad; bella, finalmente, como una obra de arte sublime:

Sus ojos son de purísimo azul, sus cabellos rubios, como el oro, sus cejas de color castaño oscuro, sus labios frescos y rojos como dos botones de rosa y el puro óvalo griego de su rostro irreprochable, tan bello en medio de su transparente palidez, completan el cuadro de la más fascinadora gracia unida a la dulzura más atrayente. (17)

La descripción se adecúa a las necesidades de la acción, Darío parece ser aquí el que pinta, el escribe el verbo bosquejar, (18) utilizará el lenguaje de la pintura en las descripciones, la intermediación artística del arte para trasladarnos la idea de belleza y pureza. Se refiere el narrador a la experiencia vivida como a una pintura, ahora en la memoria; cuando se habla del pasado desgraciado de la protagonista que el lector aún ignora: "el dolor y la desgracia parecen haber sido los colores dominantes del cuadro. (18)

Unas páginas más adelante, vuelve a aparecer otro cuadro que abunda en la belleza rara y peculiar de Emelina en Viña del mar, con un traje negro adornado con una guirnalda de rosas blancas que hacía resaltar más que de costumbre la serena palidez de su rostro. No llevaba al cuello otra cosa que un artístico medallón de oro, pendiente de una cinta de terciopelo negro, y sujetaba sus rubios y abundosos cabellos un broche de brillantes.

Y aún más tarde, vuelve de nuevo al retrato de la misma mujer en el día de su boda y bajo la mirada de su marido:

Era rubia como una espiga, blanca como la leche, y sus azules ojos parecían dos zafiros medio encerrados en broches de oro. Sus labios frescos y rojos como dos pétalos de clavel, provocaban al beso y su casi desnudo seno que subía y bajaba a impulsos da la respiración parecía el nido de pulido mármol de las dos plateadas tórtolas de Cíteres. (52) 
Al lado de la pintura, en alguna ocasión, la música también servirá para construir un texto riquísimo y sonante:

Las notas se escapaban del instrumento como los pájaros de una jaula, que al salir hicieron gala de su tesoro de trinos y gorgeos. Subían alegres, armónicamente confundidas como en un torbellino, hasta los ruidosos acordes del crescendo y bajaban, como traídas a tenue soplo de alas impalpables, tristes, como un coro de suspiros. (81)

Las apelaciones al lector son frecuentes, tanto desde el punto de vista de la construcción de la historia como de la elaboración de la estructura; se le tiene en cuenta y se realiza la novela para él. Sin embargo, ese recurso, unido a la declaración antirrealista del prólogo nos lleva a concluir que existe en su uso una intención de marcar esa voluntad antimimética. Es reseñable la intervención activa del que narra los acontecimientos, que se acumulan, para detenerlos o avanzarlos; así sucede cuando se nos cuenta la boda de Emelina y el conde Du Venier, ceremonia de gran lujo a la que asiste el Príncipe de Gales, Alfredo Tenyson y el Ilustre americano, en un gradación humorística y delirante. En medio de los fastos, el narrador nos indica:

Antes de que llegue el momento de firmar los contratos, narraremos por vía de curiosidad algunas circunstancias especiales de aquella noche.

Y continúan llegando los invitados, Alfredo Tenyson al que le cede el puesto el príncipe de Gales y el Ilustre americano, el general don Antonio Guzmán Blanco... (48).

Y no sigue narrando: "y así sucesivamente", escribe, apelando a nuestra imaginación para completar el cuadro.

"No describiremos esa escena de juego" (63); el relato del mundo de los jugadores a los que pertenece el marido de Emelina, una hermandad criminal que ostenta un banco y que incrementa su patrimonio con el robo en partidas amañadas: Parini - de la Cueva, rue Michelet, París. (70)

En la tercera parte aparecerá un narrador que interpela a los jóvenes hombres y mujeres de la sociedad que retrata en relación a un asunto que, como ya se ha dicho, tiene un papel central en la trama, el dinero:

El conde tiene dinero. Lo cual es una felicidad que puede traer hasta la beatitud. ¿No es cierto, hermosas niñas? ¿mentimos, perfumados caballeritos que andáis a la caza de una beldad tan perfecta que la queréis con dote y todo? (87). Y también, "por lo pronto, las niñas, para ser guapas deben llevar por ojos dos libras esterlinas. En vez de buenos días se saludarán buenos duros. El mayor piropo que se puede espetar a una belleza es el de Bartrina...Milloncito de mi alma! (87)

En este capítulo, la historia se suspende por la introducción de esta reflexión y de un diálogo en el que, alguien, entendemos que uno de los autores, pregunta sobre si esto es así en todas partes, a lo que le responde el otro autor, que sí, que "En Madrid como en Santiago y en San Petersburgo como en Río de Janeiro". (87)

A la pregunta sobre el deber, la respuesta es:

Ha bajado, y se cotiza a ínfimo precio.

--Y el amor? Como artículo de necesidad, se paga bien, pero no el platónico.

--Y la poesía?

--Ya lo dijo Gustavo Bécquer. Una oda solo es buena de un billete de banco al dorso escrita. (88)

Este diálogo humorístico plantea muy en serio los nuevos valores sociales, los mismos que rigen en la sociedad en la que la novela se desarrolla. Ante tal situación, "los autores a dúo, exclaman - ¿Oh realidad amarga de la vida!" (88)

Pero el lector convertido en personaje, está esperando por los hechos: "El lector, interrumpiendo: -- Pero, ¿y la novela?” (88) Y al fin, los autores responden: “-- Para allá vamos.” (90). Y continúa la narración sobre la vida de los esposos du Venier, trasladada desde un tono humorístico.

En este apartado de introducción de nuevos recursos en la narración convencional, encontramos, en el capítulo III de la tercera parte titulado "Dos artículos de diario" (98), exactamente lo que reza en el título, dos artículos, uno tomado de Commercial Review y otro de Pall Mall Gazette. Los artículos aparecen 
entrecomillados, y traducidos ... por los autores/narradores "que también traducimos", precisan (99). Los dos artículos tratan el mismo asunto desde dos enfoques diferentes. El tema es la quiebra de la Banca Parini, de la Cueva y Cia, por descubiertos enormes, y por la fuga de su cajero a los Estados Unidos (Josuah Humburg); la noticia de Pall Mall Gazette habla de las actividades criminales de una banda formada por conocidos nombres de las finanzas, que cometen espantosos crímenes en las salas de juego; la cofradía del Guante Rojo, a la que pertenecen los banqueros y también el esposo de Emelina.

Las noticias introducidas aquí sirven para volver al pasado y dar una explicación a lo que la prensa se pregunta, y que los autores narradores saben ya, con el fin de desenmascarar al conde du Venier, el desdeñoso marido de Emelina.

"Retrocedamos" (104) se titula significativamente el capítulo IV de la tercera parte. Y retroceden los narradores un año y medio hasta Montecarlo; en un lugar clandestino de juego, el conde francés pierde toda su fortuna y el banquero Parini le propone casarse con la rica heredera con el fin de cobrar con creces su deuda y hacer cómplice a Ernesto de sus delitos de fraude en el juego y posteriormente de asesinato. Dinero es la clave, es el peligro, es la causa, absque argento, gloria vana es la leyenda que reza en la medalla de la cofradía del crimen, la sociedad del guante rojo que denomina a los asesinatos "supresiones". Ernesto suprimirá a su suegro por consejo de Parini para obtener más dinero. El humor crítico predomina sobre la tragedia, cuando los narradores informan al lector de la impericia de los facultativos que diagnosticaron muerte por gravísima enfermedad del corazón cuando en el escritorio del conde se veía un pomo vacío de una sustancia extraña y en la etiqueta podía leerse: "Digitaline pure. Eviter les contrefacons." (140)

La cuarta parte, instalada en el presente de la narración, al igual que la primera, trae a los personajes bondadosos a Chile, nótese que los criminales son europeos, y comienza en la primavera y con una representación teatral en Santiago.

Se abre el telón y aparecen los cinco personajes nobles; dos parejas, Gavidia y Emelina; Sara y Vergara, y un tío de la huérfana protagonista que sustituye al padre. Los narradores se ofrecen a reflejar lo que piensan los personajes masculinos, los novios, no lo que dicen, puesto que las palabras íntimas no salen de los labios, pero si están en el pensamiento. Advierten de que lo reflejarán de manera simultánea, lo cual resulta interesante, ya que la simultaneidad no hará converger en uno los discursos todavía, pero se hacen intentos gráficos para marcar este recurso y unas líneas de puntos y espacios separan los diferentes fragmentos.

"Dos cartas" constituirán el capítulo II de la cuarta parte (184); en ellas se relata el mismo acontecimiento de manera simultánea y desde dos voces; el suceso es el duelo que mantuvo José María Vergara en Bruselas con un bravucón que resultaría ser du Venier y que afirmaba que los chilenos eran unos cobardes y unos ladrones, a propósito de la guerra del Pacífico; es sabido que la introducción de temas nacionales atrae al público y a la vez resulta educativo.

El final de la novela es apresurado; capítulo III "En que se adelanta la narración" (190) y se esfuerza por introducir recursos narrativos nuevos, como una conversación telefónica, dos en realidad, en las que escuchamos o leemos únicamente lo que dice uno de los interlocutores, escatimando datos al lector, aunque fácilmente podría recomponer la conversación y eso se le exige a ese lector que ha aprendido tanto de la historia como de la elaboración literaria, supuestamente porque ha acompañado a los autores/narradores a lo largo de la obra.

La nueva boda de Emelina y Gavidia y Sara y Vergara acelera el final; y se introduce una explicación: "los autores tienen a bien ahorrar tiempo y paciencia al lector, con nuevos párrafos que podrían espetarle, con el tema: de lo rico que es estar de novio." (192)

Podrían y no lo harán, porque lo respetan y saben que su inteligencia puede suplir las líneas de puntos que marcan la ausencia de esos párrafos con materiales de su propia invención. Los narradores/ autores no cuentan más.

Emelina es una novela con intencionales rasgos de folletín, también es paródica de sí misma, y contiene fragmentos de prosa exquisita, que despliega una visión satírica de la sociedad moderna, y lúcida sobre el papel desempeñado por el dinero, entre otras cuestiones sociales.

Técnicamente, utiliza recursos que serán elaborados posteriormente por la vanguardia, como las apelaciones al lector, la introducción del autor en el texto, cierta exhibición del proceso de elaboración de la obra, la narración por medio de textos externos como las noticias de prensa y las cartas leídas por los personajes, alejando así la verosimilitud frente a lo verídico reclamado desde la ficción.

Estructuralmente, presenta una visión fragmentaria y simultánea del mundo, ensayando diferentes puntos de vista de los hechos. El uso del teatro dentro de la narración pone distancia con los acontecimientos narrados; lo mismo sucederá con las conversaciones telefónicas, que nos hacen conscientes del espacio, del tiempo, de la fragmentariedad de nuestra percepción. 
El ensayo del simultaneísmo y la visión a través, en omnisciencia extrema, marcado gráficamente en el texto, dota de singularidad a la obra; y un núcleo temático radial, identificado con el dinero como generador de emociones y pulsiones oscuras, mueve la historia, se adueña de la acción, más allá del amor, la bondad y la maldad.

La incorporación de las citadas técnicas de ficción ${ }^{10}$ novedosas, como la introducción de cartas, artículos de prensa, conversaciones telefónicas, rudimentos de simultaneidad y también el fragmentarismo y la ruptura constante de la sucesión temporal, nos acercaría al lenguaje artístico de la vanguardia histórica.

\section{Referencias bibliográficas}

Arellano, Jorge Eduardo (2013), “Darío: el novelista que intentó ser”, Anales de Literatura hispanoamericana, vol. 42, pp.135-149.

Darío, Rubén (1915). La vida de Rubén Darío escrita por el mismo. Barcelona: Casa Mauci. Disponible en: http://www.cervantesvirtual.com/obra-visor/la-vida-de-ruben-dario--0/html/ff17bf78-82b1-11dfacc7-002185ce6064 2.html.

Darío, Rubén (1927). Emelina. Novela en colaboración de Eduardo Poirier. Estudio preliminar de Francisco Contreras. Paris: Agencia Mundial de Librería.

Phillipps-López, Dolores (1998), "Rubén Darío y la novela", en C. Cuevas y E. Baena (coords.). Rubén Darío y el arte de la prosa: ensayo, retratos y alegorías. Málaga: Universidad de Málaga, pp.211-226.

Poirier, Eduardo y Rubén Darío (1887). Emelina. Valparaíso: Imprenta y Litografía Universal de Chaigueau y Castro [Eduardo Poirier figura como coautor antes de Darío].

Schulman, Ivan (2002), "El oro de Mallorca: ¿novela inconclusa?”, en El proyecto inconcluso. La vigencia del modernismo. México: Siglo XXI, pp.93-216.

Silva Castro, Raúl (1934). Obras desconocidas de Rubén Darío. Escritas en Chile y no recogidas en ninguno de sus libros. Santiago de Chile: Prensas Universitarias de Chile.

Silva Castro, Raúl (1956). Rubén Darío a los veinte años. Madrid: Gredos.

Vargas Llosa, Mario (1984), "El folletín por entregas y el serial”, Anàlisi 9, 1984.

Zamudio Zamora, José (1973). La novela histórica en Chile. Buenos Aires: Editorial Francisco de Aguirre.

${ }^{10}$ Emelina puede leerse en el mismo rango que sitúa el crítico norteamericano Ivan Schulman El oro de Mallorca, identificando el fragmentarismo como un signo de irrupción de una germinal vanguardia. Reconoce, en ese texto dariano, igualmente la inestabilidad narrativa y la hibridación de las técnicas de ficción como signos del mismo proceso. 